\title{
Genetic parameters and relationships between fibre and type traits in two breeds of Peruvian alpacas
}

\author{
I. Cervantes a, M.A. Pérez-Cabal ${ }^{\mathrm{a}}$, R. Morante ${ }^{\mathrm{b}}$, A. Burgos $^{\mathrm{b}}$, C. Salgado $^{\mathrm{a}}$, B. Nieto ${ }^{\mathrm{a}}$, \\ F. Goyache ${ }^{c}$, J.P. Gutiérrez ${ }^{\mathrm{a}, *}$ \\ a Departamento de Producción Animal, Universidad Complutense de Madrid, Avda. Puerta de Hierro s/n, E-28040 Madrid, Spain \\ b PACOMARCA S.A., P.O. BOX 94, Av. Parra 324, Arequipa, Peru \\ c SERIDA-Somió, C/Camino de los Claveles 604, E-33203 Gijón (Asturias), Spain
}

\section{A R T I C L E I N F O}

\section{Article history:}

Received 23 July 2009

Received in revised form 21 October 2009

Accepted 26 October 2009

Available online 6 December 2009

\section{Keywords:}

Peruvian Altiplano

Alpaca

Fibre traits

Type traits

Genetic parameters

\begin{abstract}
A B S T R A C T
Four fibre traits (fibre diameter, FD; coefficient of variation of FD, comfort factor; and standard deviation of FD) were jointly analysed with six subjectively scored type traits (fleece density, crimp, lock structure, head, coverage, and balance) in two breeds of Peruvian Altiplano alpaca (Suri, SU; and Huacayo, HU) to ascertain their genetic relationship. A total of 2405 fibre records and 2194 type scores were available for the HU breed whereas these figures were 709 for fibre records and 650 for type scores for the SU breed. Estimated heritabilities for fibre traits were moderate to high, ranging from 0.565 to 0.699 in the SU breed and from 0.255 to 0.417 in the HU breed. Genetic and permanent environmental correlations between fibre related traits were extremely similar across breeds suggesting that these traits are fairly the same. Heritabilities estimated for the type traits tended to be lower than those estimated for the fibre traits particularly in the SU breed (ranging from 0.173 to 0.272). Fibre and type traits were, in general, genetically poorly correlated except for crimp in the HU breed, which had favourable correlations, from moderate to high, for fibre traits. In Altiplano areas in which fibre performance recording could not be implemented, crimp scoring makes it feasible to carry out mass selection in the Huacayo breed and furthermore include rural communities in national or regional selection programmes.
\end{abstract}

(c) 2009 Elsevier B.V. All rights reserved.

\section{Introduction}

Peru produces about $90 \%$ of the world camelid fibre (CONACS, 2004). Around 95\% of the Peruvian camelid population is located in the Andes and managed under a traditional extensive systems characterized by low productive and reproductive parameters (Ministry of Agriculture, Peru, 2004). Recently, some genetic improvement programs for alpaca fibre production have been implemented

\footnotetext{
* Corresponding author at: Departamento de Producción Animal, Facultad de Veterinaria, Universidad Complutense de Madrid, Avda. Puerta de Hierro s/n, E-28040 Madrid, Spain. Tel.: +34 913943767; fax: +34913943767.

E-mail address: gutgar@vet.ucm.es (J.P. Gutiérrez).
}

in the Peruvian Altiplano, namely those run by Pacomarca S.A. (Gutiérrez et al., 2009). The Pacomarca recording organisation is based on an experimental ranch applying state-of-art technology including objective measurement of fibre quality such as fibre diameter and its coefficient of variation.

The final goal of an alpaca performance recording organisation is to establish a sire selection program for fibre quality using objective measurements as selection criteria. However, a first step could be the implementation of a performance record based on subjective scoring of type traits assessing the animal's accordance with an "ideal" alpaca as a producer of top quality fibre. This would make it possible to include traditional herds in a performance organisation without the need of ad-hoc facilities or equipment. Scoring would be performed by expert classifiers who can 
introduce the basis for genetic improvement in rural communities. On the other hand, type traits can be used as selection criteria themselves for commercial purposes. In any case, subjective scoring might also be conditioned by the breed given that fibre appearance is quite different in Huacayo and Suri breeds (Renieri et al., 2009; Frank et al., 2006; Wuliji et al., 2000). Huacayo individuals have a crimpy and bulky fleece while Suris grows a straight and compact fleece.

Recently, we have estimated the genetic parameters that affect fibre diameter and its variability in Peruvian alpacas (Gutiérrez et al., 2009). The aim of this research was to estimate genetic parameters associated with type traits and their genetic relationships with objective fibre traits while inspecting the differences in genetic parameters between breeds. Given that selection programmes have not been widely adapted among traditional herdsmen due to the underdeveloped alpaca production systems, discussion on the establishment of the usefulness in implementing a performance recording of subjective traits in traditional alpaca herds of the Peruvian Altiplano will also be addressed.

\section{Material and methods}

\subsection{Data}

Production data and pedigree information were obtained from the experimental PACOMARCA ranch as registered in the performance recording software PACO PRO 4.3 (http://www.pacomarca.com/pacomarca/ paco_pro_en.htm), developed by PACOMARCA S.A., which can be used to gather relevant production and genealogical data. Some details about PACOMARCA ranch can be found in Gutiérrez et al. (2009).

The farm breeds two known alpaca breeds, Suri (SU) and Huacayo (HU), which are managed together except that breeding is only allowed within breed. Thus, two independent data sets have to be considered.

The analysed traits were grouped in two subsets: (a) those involving mean and variability of fibre diameter; and (b) subjectively scored type traits. The first group of traits were fibre diameter (in $\mu \mathrm{m}$; FD), coefficient of variation of FD (CV), comfort factor (CF) and standard deviation of FD (SD). Mean fibre diameter (FD) was computed from washed samples after minicored and $2 \mathrm{~mm}$ snippets using an Optical Fibre Diameter Analyser (OFDA 100). CF is defined as the percentage of fibre with less than $30 \mu \mathrm{m}$. Some of these traits were already analysed (Gutiérrez et al., 2009) but they have been reanalysed in the context of scoring traits including the higher number of records. Therefore, all results presented here take into consideration the new dataset.

The second group of traits included: Density (DE), scoring the amount of follicles per square millimetre, and is performed by pressing manually on shoulder, midpoint and rump and evaluating the amount of fleece the hand can grab at once; Crimp (CR), scoring, only in HU alpacas, the number of fibre waves per centimetre and their amplitude or height; Lock structure (LS), scoring, only in SU alpacas, the integration of individual fibre into groups or locks that should well defined, independent from each other, dense and heavy; Head (HE) is determined by the size and shape of the head in accordance with the "ideal" alpaca head including correct ears and snout; Coverage ( $\mathrm{CO}$ ), scoring the presence or absence of fibre in the alpaca extremities and head; and Balance (BA), scoring the animal's general appearance with particular attention on how proportional is the animal in relation to body, neck, limps and head. Traits were scored numerically by the same classifier, as a distance from the 'optimum' for each trait, on a desirability scale from poor (1) to excellent (5): $\mathrm{DE}$, from 1 (very low fleece density) to 5 (very dense fleece); $C R$, from 1 (very low frequency and no amplitude in crimp) to 5 (high frequency and medium amplitude); LS, from 1 (very independent, defined and uniformly distributed locks) to 5 (poorly independent and not uniformly distributed locks); HE, from 1 (long snout and ears resembling Llama-like head) to 5 (small rounded head with short snout and proportional ears); CO, from 1 (open face and very little fibre on the legs) to 5 (fibre covering toes and even producing wool blindness); and BA, from 1 (disproportional body, legs and/or neck) to 5 (correct proportion among all body parts).

Records obtained from the PACO PRO database were edited in order to exclude animals with identification errors or ambiguous birth dates. The availability of age at recording was mandatory and ranged from 0 (the birth day) to 5164 days.

The number of $\mathrm{HU}$ individuals was 2405 with fibre record and 2194 with type score records while these figures were 709 and 650, respectively, for the SU breed. Given that genetic selection is carried out in the HU white animals, those individuals were classified according to coat colour in two classes: white (69\%), other coat colour (31\%), while no distinction was made for the SU breed.

Pedigree was traced back until foundation of the performance recording thus totaling $3055 \mathrm{HU}$ and $900 \mathrm{SU}$ animals in the pedigree files. Final structure of the analysed data was dependent on the group of traits and the breed involved in each analysis (Table 2). The total number of records available in the HU breed was 5409 for the first group of traits and 2194 for the second one, while these figures were 1532 and 650 for the SU breed. Abbreviations, scoring units, means and standard deviations of traits for both breeds are in Table 2.

\subsection{Genetic analyses}

Genetic parameters were estimated via a multitrait REML procedure applied to mixed linear models. The models fitted for genetic analyses included the following fixed effects: month-year of recording as contemporary group (33 levels in both breeds), colour (only in HU, 2 levels), sex (male or female) and the age at shearing in days as a linear and quadratic covariant. When a level of the contemporary group included less than five records, they were included in the closest temporal level.

The linear animal model fitted was $\mathbf{y}=\mathbf{X b}+\mathbf{Z u}+\mathbf{W} \mathbf{p}+\mathbf{e}$ for the fibre traits and $\mathbf{y}=\mathbf{X b}+\mathbf{Z u}+\mathbf{e}$ for the type traits, with:

$$
\left(\begin{array}{l}
\mathbf{u} \\
\mathbf{p} \\
\mathbf{e}
\end{array}\right) \approx \mathbf{N}\left(\left[\begin{array}{l}
0 \\
0 \\
0
\end{array}\right],\left[\begin{array}{lll}
\mathbf{G} & 0 & 0 \\
0 & \mathbf{P} & 0 \\
0 & 0 & \mathbf{R}
\end{array}\right]\right)
$$

$\mathbf{G}=\mathbf{A} \otimes \mathbf{G}_{\mathbf{0}}, \mathbf{P}=\mathbf{I}_{\mathbf{p}} \otimes \mathbf{P}_{\mathbf{0}}, \mathbf{R}=\mathbf{I}_{\mathbf{e}} \otimes \mathbf{R}_{\mathbf{0}}$, and $\mathbf{y}$ is the vector of observations, $\mathbf{X}$ the incidence matrix of fixed effects, $\mathbf{Z}$ the incidence matrix of animal effect, $\mathbf{W}$ the incidence matrix of permanent environmental effect, $\mathbf{b}$ the vector of unknown parameters for fixed effect, $\mathbf{u}$ the vector of unknown parameters for direct animal genetic, $\mathbf{p}$ the vector of unknown parameters permanent environmental, $\mathbf{e}$ the vector of residuals, $\mathbf{I}_{\mathbf{e}}$ the identity matrix of equal order to the number of records, $\mathbf{I}_{\mathbf{p}}$ the identity matrix of equal order to the number of permanent environmental subclasses, $\mathbf{A}$ the numerator relationship matrix, $\mathbf{R}_{\mathbf{0}}$ the residual covariance matrix among measurements on the same animal, $\mathbf{G}_{\mathbf{0}}$ the covariance matrix for additive genetic effects, $\mathbf{P}_{\mathbf{0}}$ the covariance matrix for permanent environmental effects and $\otimes$ the Kronecker product.

All runs were carried out using the VCE v.5.0 program (Neumaier and Groeneveld, 1998).

\section{Results}

Average values of the analysed traits in the HU breed were $23.07 \mu \mathrm{m}$ for $\mathrm{FD}, 23.31 \%$ for $\mathrm{CV}, 5.35 \mu \mathrm{m}$ for SD and $87.73 \%$ for CF. The respective values for the SU breed were less favourable, with $24.73 \mu \mathrm{m}$ for FD, $26.00 \%$ for $\mathrm{CV}$, $6.43 \mu \mathrm{m}$ for SD and $80.91 \%$ for CF (Table 1 ).

Fig. 1 shows, for each breed, the distribution of the scores for the type traits assessed. Score 3 was the most frequent for all the type traits whereas those on the extremes ( 1 and 5) were the less frequent. Scores resembled Gaussian distributions giving confidence in the type traits scoring.

Heritabilities and genetic correlations for all the analysed traits estimated in both the HU and the SU breeds are given in Table 3. Note that two separate estimations were carried out for the two breeds unlike the previous analysis by Gutiérrez et al. (2009). 
Table 1

Mean, standard deviation (sd), scoring and abbreviations of all traits in Huacaya (HU) and Suri (SU) breeds.

\begin{tabular}{llcr}
\hline Trait & Breed & Mean & sd \\
\hline Fibre diameter (FD) & HU & 23.07 & 4.26 \\
& SU & 24.73 & 5.01 \\
Standard deviation of FD (SD) & HU & 5.35 & 1.19 \\
& SU & 6.43 & 1.67 \\
Comfort factor (CF) & HU & 87.73 & 15.58 \\
& SU & 80.91 & 19.46 \\
Coefficient of variation of FD (CV) & HU & 23.31 & 3.56 \\
& SU & 26 & 4.01 \\
Density (DE) & HU & 3.28 & 0.73 \\
& SU & 3.19 & 0.56 \\
Crimp (CR) & HU & 2.8 & 0.96 \\
Lock Structure (LS) & SU & 2.87 & 0.76 \\
Head (HE) & HU & 3.13 & 0.84 \\
& SU & 2.92 & 0.61 \\
Coverage (CO) & HU & 3.02 & 0.84 \\
Balance (BA) & SU & 3.12 & 0.74 \\
& HU & 3.15 & 0.58 \\
\hline
\end{tabular}

FD and SD in $\mu \mathrm{m}$; $\mathrm{CV}$ and $\mathrm{CV}$ in \%; DE, CR, $\mathrm{LS}, \mathrm{HE}, \mathrm{CO}$ and $\mathrm{BA}$ scored from 1 to 5 .

All the estimated heritabilities for fibre traits were moderate to high, but higher in the SU breed (ranging from 0.565 to 0.699 ) than in the HU breed (ranging from 0.255 to 0.417 ). The significance of correlations was checked by using the standard error to construct confidence interval for each. Both the HU and the SU breeds showed the same pattern: all the genetic correlations between fibre traits were significant $(p<0.05)$ except for the pair FD-CV. Again, note that this analysis was done independently for each breed unlike the Gutierrez et al. (2009) study.

The heritabilities estimated for the type traits tended to be lower than those estimated for the fibre traits particularly in the SU breed (ranging from 0.173 to 0.272 ). The genetic correlations estimated between type traits were significant for all the cases.

The genetic correlations between fibre and type traits were, in general, from moderate to low. Significance and magnitude of genetic correlations between fibre and type traits were higher in the HU breed. Thus, only 8 out of 20 trait pairs were statistically significant $(p<0.001)$ in the SU (a) HU breed

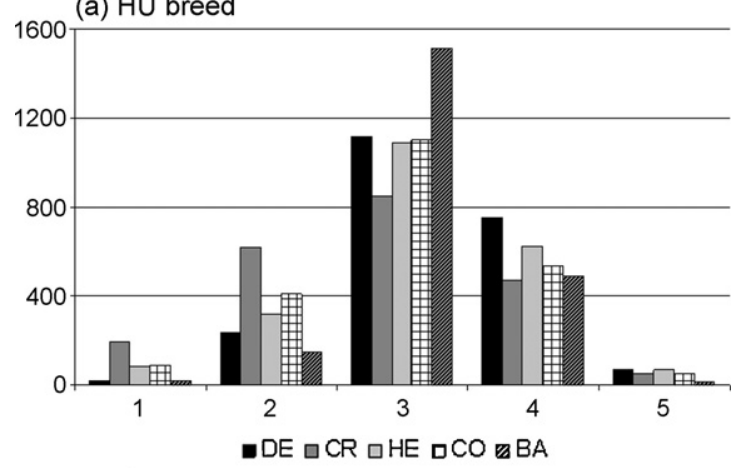

(b) SU breed

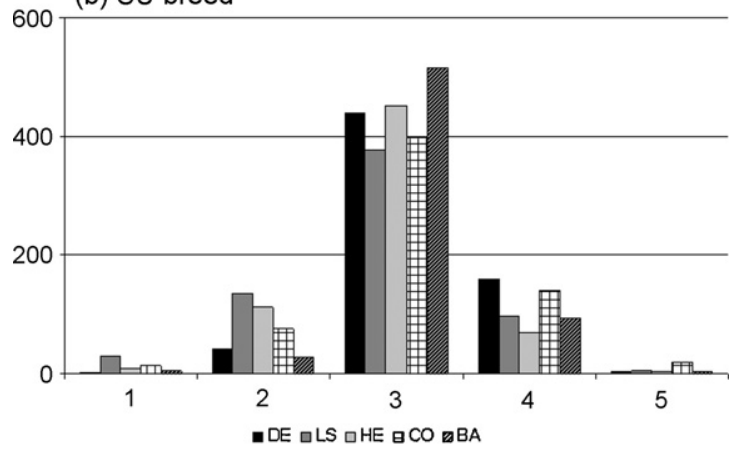

Fig. 1. Distribution of scores for type traits in (a) HU breed and (b) SU breed. See text and Table 1 for abbreviations.

breed (the group of DE, HE and BA type traits with the group of FD, SD and CF fibre traits except SD-DE). However, only FD-CO was non-significant $(p<0.05)$ for HU breed. The definition of CR either LS traits provided another important difference given that LS is only slightly genetically correlated $(p<0.05)$ with $\mathrm{FD}, \mathrm{SD}$ and CF while CR is highly genetically correlated $(p<0.001)$ with all the fibre traits.

The permanent environmental variance component (as a ratio between the permanent environmental and the phenotypic variances) estimated for the fibre traits are given in Table 4 . In general, this component was half or lower than the heritability of the corresponding trait. The repeatability values ranged between 0.41 and 0.57 in the HU breed, but they were substantially higher (ranging from 0.79 to 0.90 ) in the SU breed. The correlations between permanent environmental effects were of the same sign and similar

Table 2

Structure of data used for the estimation of genetic parameters for fibre and type traits in Huacaya (HU) and Suri (SU) breeds.

\begin{tabular}{|c|c|c|c|c|}
\hline \multirow[t]{2}{*}{ Structure of data } & \multicolumn{2}{|l|}{$\mathrm{HU}$} & \multicolumn{2}{|l|}{ SU } \\
\hline & Fibre traits & Type traits & Fibre traits & Type traits \\
\hline Records & 5409 & 2194 & 1532 & 650 \\
\hline Animals with record & 2703 & 2194 & 766 & 650 \\
\hline Average number of records per animal & 1.48 & 1 & 1.60 & 1 \\
\hline Sires with progeny in data & 52 & 51 & 22 & 22 \\
\hline Average offspring per sire & 23.1 & 25.5 & 14.4 & 15.8 \\
\hline Females with progeny in data & 587 & 490 & 159 & 136 \\
\hline Sires with record and offspring & 40 & 16 & 14 & 6 \\
\hline Females with record and offspring & 580 & 250 & 145 & 64 \\
\hline Sire-offspring pairs & 1115 & 282 & 219 & 95 \\
\hline Female-offspring pairs & 1330 & 415 & 312 & 99 \\
\hline
\end{tabular}


Table 3

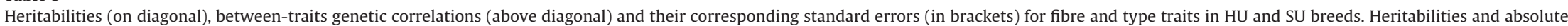
value of correlations higher than 0.30 are in bold. See text and Table 1 for abbreviations.

\begin{tabular}{|c|c|c|c|c|c|c|c|c|c|}
\hline HU breed & FD & SD & $\mathrm{CF}$ & CV & $\mathrm{DE}$ & CR & $\mathrm{HE}$ & $\mathrm{CO}$ & BA \\
\hline FD & $0.369(0.012)$ & $\mathbf{0 . 7 1 9}^{* * *}(0.010)$ & $-0.968^{* * *}(0.003)$ & $0.094^{* * *}(0.026)$ & $-0.079^{* *}(0.029)$ & $-0.300^{* * *}(0.025)$ & $-0.279^{* * *}(0.017)$ & $0.028^{\mathrm{NS}}(0.020)$ & $-0.134^{* * *}(0.022)$ \\
\hline SD & & $\mathbf{0 . 4 1 7}(0.013)$ & $-\mathbf{0 . 7 9 0}^{* * *}(0.011)$ & $\mathbf{0 . 7 5 1}^{* * *}(0.011)$ & $-0.257^{* * *}(0.029)$ & $-0.520^{* * * *}(0.023)$ & $-0.123^{* * *}(0.019)$ & $0.110^{* * *}(0.020)$ & $-0.063^{* *}(0.024)$ \\
\hline CF & & & $\mathbf{0 . 2 5 5}(0.011)$ & $-0.219^{* * *}(0.027)$ & $0.108^{* * *}(0.032)$ & $\mathbf{0 . 3 3 2}{ }^{* * *}(0.027)$ & $0.236^{* * *}(0.020)$ & $-0.077^{* *}(0.024)$ & $0.102^{* * *}(0.026)$ \\
\hline $\mathrm{CV}$ & & & & $\mathbf{0 . 3 8 0}(0.011)$ & $-0.296^{* * *}(0.033)$ & $-0.477^{* * *}(0.029)$ & $0.105^{* * *}(0.023)$ & $0.148^{* * *}(0.024)$ & $0.059^{*}(0.028)$ \\
\hline $\mathrm{DE}$ & & & & & $0.236(0.009)$ & $\mathbf{0 . 7 2 5}^{* * *}(0.026)$ & $0.209^{* * *}(0.036)$ & $-0.145^{* * *}(0.041)$ & $0.214^{* * *}(0.044)$ \\
\hline CR & & & & & & $0.420(0.010)$ & $\mathbf{0 . 3 3 0}^{* * *}(0.029)$ & $0.086^{*}(0.034)$ & $\mathbf{0 . 3 6 7}^{* * *}(0.034)$ \\
\hline $\mathrm{HE}$ & & & & & & & $\mathbf{0 . 4 2 5}(0.012)$ & $\mathbf{0 . 7 6 5}^{* * *}(0.022)$ & $\mathbf{0 . 9 2 1}^{* * *}(0.019)$ \\
\hline $\mathrm{CO}$ & & & & & & & & $\mathbf{0 . 4 7 5}(0.009)$ & $\mathbf{0 . 8 2 6}^{* * *}(0.021)$ \\
\hline BA & & & & & & & & & $\mathbf{0 . 1 4 8}(0.013)$ \\
\hline SU breed & FD & SD & $\mathrm{CF}$ & $\mathrm{CV}$ & $\mathrm{DE}$ & LS & $\mathrm{HE}$ & $\mathrm{CO}$ & BA \\
\hline FD & $0.699(0.018)$ & $\mathbf{0 . 7 5 0}^{* * *}(0.022)$ & $-0.975^{* * *}(0.005)$ & $0.087^{\mathrm{NS}}(0.049)$ & $0.284^{* * *}(0.069)$ & $-0.193^{*}(0.083)$ & $-0.036^{* * *}(0.088)$ & $0.166^{*}(0.071)$ & $0.034^{* * *}(0.076)$ \\
\hline SD & & $0.684(0.019)$ & $-\mathbf{0 . 7 5 9}^{* * *}(0.025)$ & $\mathbf{0 . 7 1 9}^{* * *}(0.025)$ & $0.141^{*}(0.070)$ & $-0.154^{*}(0.083)$ & $-0.010^{* * *}(0.084)$ & $0.131^{*}(0.066)$ & $-0.020^{* * *}(0.073)$ \\
\hline $\mathrm{CF}$ & & & $0.565(0.021)$ & $-0.138^{* *}(0.052)$ & $-0.334^{* * *}(0.070)$ & $0.224^{*}(0.090)$ & $0.016^{* * *}(0.095)$ & $-0.186^{*}(0.074)$ & $-0.049^{* * *}(0.085)$ \\
\hline $\mathrm{CV}$ & & & & $\mathbf{0 . 6 0 5}(0.026)$ & $-0.056^{\mathrm{NS}}(0.073)$ & $-0.018^{\mathrm{NS}}(0.080)$ & $0.038^{\mathrm{NS}}(0.069)$ & $0.039^{\mathrm{NS}}(0.058)$ & $-0.052^{\mathrm{NS}}(0.056)$ \\
\hline DE & & & & & $\mathbf{0 . 2 6 8}(0.054)$ & $\mathbf{0 . 4 3 3}^{* * *}(0.137)$ & $\operatorname{0.719}^{* * *}(0.108)$ & $\mathbf{0 . 7 9 0}^{* * *}(0.070)$ & $\mathbf{0 . 5 7 9}^{* * *}(0.125)$ \\
\hline LS & & & & & & $0.222(0.044)$ & $\mathbf{0 . 6 3 7}^{* * *}(0.086)$ & $\mathbf{0 . 4 1 7}^{* *}(0.134)$ & $\mathbf{0 . 6 8 2}^{* * *}(0.064)$ \\
\hline $\mathrm{HE}$ & & & & & & & $\mathbf{0 . 1 7 3}(0.042)$ & $\mathbf{0 . 7 8 5}^{* * *}(0.085)$ & $\mathbf{0 . 9 4 1}^{* * *}(0.052)$ \\
\hline $\mathrm{CO}$ & & & & & & & & $0.272(0.046)$ & $\mathbf{0 . 7 3 0}^{* * *}(0.092)$ \\
\hline BA & & & & & & & & & $\mathbf{0 . 2 5 6}(0.050)$ \\
\hline
\end{tabular}

Significance level: $p<0.05$.

** Significance level: $p<0.01$.

*** Significance level: $p<0.001$

NS Non-significant. 


\section{Table 4}

Permanent environmental by phenotypic variances ratio (on diagonal), between-traits permanent environmental correlations (above diagonal), Repeatabilities (last row, R), and their corresponding standard errors (in brackets), for fibre traits in HU and SU breeds. Absolute value of correlations higher than 0.30 are in bold. See text and Table 1 for abbreviations.

\begin{tabular}{|c|c|c|c|c|c|c|c|c|}
\hline & \multicolumn{4}{|l|}{ HU breed } & \multicolumn{4}{|l|}{ SU breed } \\
\hline & FD & SD & $\mathrm{CF}$ & $\mathrm{CV}$ & FD & SD & $\mathrm{CF}$ & $\mathrm{CV}$ \\
\hline FD & $0.180(0.009)$ & $0.587^{* * *}(0.028)$ & $-0.957^{* * *}(0.008)$ & $-0.231^{* * *}(0.036)$ & $0.198(0.034)$ & $\mathbf{0 . 7 9 3}^{* * *}(0.066)$ & $-\mathbf{0 . 8 1 8}^{* * *}(0.034)$ & $0.065^{\mathrm{NS}}(0.128)$ \\
\hline SD & & $0.138(0.008)$ & $-\mathbf{0 . 5 6 5}^{* * *}(0.030)$ & $\mathbf{0 . 6 4 7}^{* * *} 0.015$ & & $0.163(0.025)$ & $-\mathbf{0 . 7 6 6}^{* * *}(0.093)$ & $\mathbf{0 . 6 5 8}^{* * *} 0.073$ \\
\hline $\mathrm{CF}$ & & & $0.160(0.008)$ & $0.182^{* * *}(0.037)$ & & & $0.273(0.046)$ & $-0.268^{* *}(0.102)$ \\
\hline $\mathrm{CV}$ & & & & $0.193(0.010)$ & & & & $0.183(0.042)$ \\
\hline $\mathbf{R}$ & $0.550(0.015)$ & $0.554(0.015)$ & $\mathbf{0 . 4 1 4}(0.014)$ & $0.573(0.015)$ & $0.897(0.038)$ & $0.847(0.031)$ & $\mathbf{0 . 8 3 8}(0.051)$ & $\mathbf{0 . 7 8 9}(0.050)$ \\
\hline
\end{tabular}

magnitude as those for the corresponding genetic correlations.

\section{Discussion}

\subsection{Fibre traits}

To our knowledge, this is the first time in which genetic parameters have been estimated separately in the HU and the SU breeds for fibre traits (see Frank et al., 2006 and Gutiérrez et al., 2009, for reviews) and the first report on genetic analysis of type traits in alpaca. The estimated heritabilities for FD and CV in the HU breed were slightly lower than those recently reported in the same population by Gutiérrez et al. (2009), when both breeds were jointly analysed but including the breed as a fixed factor of the estimation model fitted. However, those heritabilities estimated in the SU breed for the same traits are substantially higher (above 0.6). This scenario is basically the same for the other two fibre traits analysed (SD and CF). Reported heritabilities for fibre traits in New Zealand (Wuliji et al., 2000 ) or Australian alpacas (Ponzoni et al., 1999) are within the range reported here for the SU breed. Frank et al. (2006) suggested that fibre traits heritabilities estimated in alpaca tended to be low to moderate in the high plateau environment and very high outside Altiplano conditions. From our results, we can argue that there are major genes influencing fibre traits segregating in different alpaca populations. In our case, these putative major genes would segregate, at least, in the SU breed.

Even though estimates obtained in the two breeds are completely independent, the genetic and permanent environmental correlations between fibre related traits were extremely similar (Table 3). Among these correlations, that between FD and $\mathrm{CF}(-0.968$ in $\mathrm{HU}$ breed and -0.975 in SU breed) suggests that they are basically the same trait. The genetic correlations between $\mathrm{CF}$ and the other two traits related to fibre variability were negative and from moderate (CF-CV) to high (CF-SD) in both the HU and the SU breeds showing that $\mathrm{CF}$ is much more genetically related with the thinness of the fibre than with its variability. Moreover, genetic correlations for FD-CV are substantially lower than those estimated for FD-SD thus suggesting that the main relationship between the trait (FD) and its variability is due to a scale effect. As heritability estimated for $\mathrm{CV}$ is not low (0.38 and 0.61 in $\mathrm{HU}$ and SU breeds, respectively), both
CV and SD traits, with both trying to address the same thinness variability concept, seem however, not to be exactly the same trait from a genetic point of view. The interest in reducing the variability of the fibre diameter can be inferred from the recording of several related traits, directly such as $\mathrm{SD}$ or $\mathrm{CV}$, or indirectly such as CF. This is an important commercial trait since it measures the "prickle factor" of the garment. The heritability values for these traits make the goal of reducing the variability by selecting directly for SD or $\mathrm{CV}$ realistic. However, approaches dealing with genetics of variability (Gutiérrez et al., 2006) should be essayed.

\subsection{Type traits}

Heritabilities estimated for type traits were, in general, moderate to high in the HU breed and moderate to low in the SU breed. In contrast with fibre traits genetic correlations between type traits showed different patterns in each breed. This suggests that the classifier assesses different aspects for each trait depending on the breed. In the SU breed, type traits seem to characterise the features of a breed standard, by showing that all the type trait pairs have high genetic correlations. This is especially true for the overall appraisal of the individual's appearance (BA) and the correctness of the head (HE) that has the highest genetic correlations of this subset of traits. However, in the HU breed those type traits characterising the most production ability of the individual (DE and CR) had a high genetic correlation (0.725) but have poor genetic correlations with the other type traits. This suggests that, when assessing HU individuals, the classifier is less affected by the beauty of the animal to subjectively score the ability for production of quality fibre.

Indeed, the scoring of type traits used here can be criticised. The analysed traits have a complex definition and score the deviation (positive or negative) from an 'optimum', measuring less phenotypic and genetic variation. Traits at the extremes of the observed biological (anatomical) variability could show the same low score, thus inducing a loss of biological relationships between-traits (Gutiérrez and Goyache, 2002). However, this kind of traits have been shown to have moderate to low heritabilities in other livestock species and also ability to ascertain genetic relationships between them and economically important traits (Gutiérrez and Goyache, 2002; Gutiérrez et al., 2002). In this respect, type traits are, in general, poorly correlated 
with fibre traits except for CR in the HU breed, which had favourable correlations, from moderate to high, with fibre traits. This is of special importance due to the predominance of the HU breed in the South American camelid fibre production (Lupton et al., 2006). Scoring of CR could be routinely obtained in the HU population in Peru. The genetic correlations between CR and fibre traits would not justify using the CR scoring to replace the performance recording based on objective fibre assessments. However, in areas in which such 'modern' performance recording could not be implemented, CR scoring could make it possible to carry out mass selection and further include rural communities in national or regional selection programmes.

To summarise, the CR trait would be the only one recommended as selection criteria in the HU breed if fibre traits are the objective, while the use of type traits would have a doubtful use in SU breed. In the same way, if selection objectives are the type traits themselves, the use of own traits as criteria will also be more effective in HU breed. The type classification system described here is easy to explain to breeders and can be easily understood and performed. This could potentially contribute to the homogenization of fibre yield in many areas of the Peruvian Altiplano.

\section{Acknowledgments}

This work was partially funded by a contract between PACOMARCA S.A. (http://www.pacomarca.com/) and the research group no. 920332 'Modelos de selección y evaluación de reproductores' of the Universidad Complutense de Madrid.

\section{References}

CONACS, 2004. Resumen de las actividades realizadas en el programa de repoblamiento de alpacas. Ministerio de Agricultura, Lima, Perú.

Frank, E.N., Hick, M.V.H., Gauna, C.D., Lamas, H.E., Renieri, C., Antonini, M., 2006. Phenotypic and genetic description of fibre traits in South American domestic camelids (llamas and alpacas). Small Rum. Res. 61, 113-129.

Gutiérrez, J.P., Álvarez, I., Fernández, I., Royo, L.J., Díez, J., Goyache, F., 2002. Genetic relationships between calving date, calving interval, age at first calving and type traits in beef cattle. Livest. Prod. Sci. 78, 215-222.

Gutiérrez, J.P., Goyache, F., 2002. Estimation of genetic parameters of type traits in Asturiana de los Valles beef cattle breed. J. Anim. Breed. Genet. 119, 93-129.

Gutiérrez, J.P., Goyache, F., Burgos, A., Cervantes, I., 2009. Genetic analysis of six production traits in Peruvian alpacas. Livest. Sci. 123, 193-197.

Gutiérrez, J.P., Nieto, B., Piqueras, P., Ibáñez, N., Salgado, C., 2006. Genetic parameters for canalisation analysis of litter size and litter weight traits at birth in mice. Genet. Sel. Evol. 38, 445-462.

Lupton, C.J., McColl, A., Stobart, R.H., 2006. Fiber characteristics of the Huacaya Alpaca. Small Rum. Res. 64, 211-224.

Neumaier, A., Groeneveld, E., 1998. Restricted maximum likelihood estimation of covariances in sparse linear models. Genet. Sel. Evol. 30, 3-26.

Ponzoni, R.W., Grimson, R.J., Hill, J.A., Hubbard, D.J., McGregor, B.A., Howse, A., Carmichael, I., Judson, G.J., 1999. The inheritance of and associations among some production traits in young Australian Alpacas. Proc. Aust. Assoc. Anim. Breed. Genet. 13, 468-471.

Renieri, C., Valbonesi, A., La Manna, V., Antonini, M., Asparrin, M., 2009. Inheritance od Suri and Huacaya type of fleece in Alpaca. Ital. J. Anim. Sci. 8, 83-91

Wuliji, T., Davis, G.H., Dodds, K.G., Turner, P.R., Andrews, R.N., Bruce, G.D., 2000. Production performance, repeatability and heritability estimates for live weight, fleece weight and fiber characteristics of Alpacas in New Zealand. Small Rum. Res. 37, 189-201. 